\title{
Celecoxib and Diclofenac Plus Omeprazole are Similarly Effective in the Treatment of Arthritis in Patients at High GI Risk in the CONDOR Trial ${ }^{\S}$
}

\author{
Herbert L. Kellner ${ }^{*}$, Chunming $\mathrm{Li}^{2}$ and Margaret N. Essex ${ }^{2}$ \\ ${ }^{I}$ Division of Rheumatology, Center for Inflammatory Joint Diseases, Munich, Germany \\ ${ }^{2}$ Pfizer Inc, New York, NY, USA
}

\begin{abstract}
Objective: Compare effectiveness of celecoxib versus diclofenac plus omeprazole in improving arthritis signs and symptoms in patients at high gastrointestinal (GI) risk who were enrolled in the CONDOR (Celecoxib vs Omeprazole and Diclofenac in Patients With Osteoarthritis and Rheumatoid Arthritis) trial.

Methods: CONDOR was a 6-month, prospective, double-blind, triple-dummy, parallel-group, randomized, multicenter trial comparing celecoxib $200 \mathrm{mg}$ twice daily versus diclofenac slow release (SR) $75 \mathrm{mg}$ twice daily plus omeprazole 20 mg daily. Patients were Helicobacter pylori negative, had osteoarthritis (OA) or rheumatoid arthritis (RA), were aged $\geq 60$ years, were with or without a history of gastroduodenal ulceration, or were $\geq 18$ years with previous gastroduodenal ulceration. Patients' Global Assessment of Arthritis was determined at each study visit.
\end{abstract}

Results: A total of 4484 patients were randomized to treatment (2238 celecoxib, 2246 diclofenac SR) and included in the intention-to-treat analyses. Least squares mean (LSM) (standard error [SE]) for Patients' Global Assessment of Arthritis was $3.219(0.017)$ and $3.221(0.017)$ at baseline for celecoxib and diclofenac $S R(p=0.90)$. Improvement in both groups was similar in months 2, 4, and 6; at month 1 the LSM (SE) was 2.647 (0.017) and 2.586 (0.017) for celecoxib and diclofenac $(\mathrm{p}=0.0025)$. LSM difference (SE) from baseline to final visit demonstrated an improvement of $0.75(0.02)$ in celecoxib-treated patients and $0.77(0.02)$ in diclofenac SR-treated patients $(\mathrm{p}=0.42)$.

Conclusions: Celecoxib and diclofenac plus omeprazole were shown to have similar efficacy in patients with OA and/or RA at increased GI risk who were enrolled in the CONDOR trial.

Trial Registry: Trial was registered under ClinicalTrials.gov identifier NCT00141102.

Keywords: Arthritis, GI, NSAIDs.

\section{INTRODUCTION}

Treatment goals in patients with arthritis focus on reducing pain and inflammation, and on improving functional activity $[1,2]$. Nonsteroidal anti-inflammatory drugs (NSAIDs), including nonselective NSAIDs and cyclooxygenase-2 (COX-2) selective NSAIDs, are used widely in the management of pain and inflammation associated with osteoarthritis (OA) and rheumatoid arthritis (RA) [3].

Although the efficacy of nonselective NSAIDs in arthritis is well established, use of these agents is associated with numerous adverse events, including upper and lower gastrointestinal (GI) toxicity [4-9]. All prescription NSAIDs have the same warning for serious GI events from the US Food and Drug Administration [10]. Physicians are faced

*Address correspondence to this author at the Division of Rheumatology, Center for Inflammatory Joint Diseases, KH Neuwittelsbach, Romanstr. 9, 80639 München, Germany; Tel: 089 / 13 959-100; Fax: 089 / 13 959-102; E-mail: hk@prof-dr-kellner.de

${ }^{\S}$ These data were presented at the European League Against Rheumatism annual congress, London, UK, 27 May 2011. Abstract No. FRI0125. Ann Rheum Dis 2011; 70(suppl 3): 386. with a difficult clinical decision in selecting the best treatment option for individual patients, particularly those at high risk of GI events, that balances effectiveness against arthritis signs and symptoms alongside the potential for adverse events.

COX-2 selective NSAIDs were developed to potentially reduce the GI adverse events caused by nonselective NSAIDs [11] while retaining similar efficacy [12]; several lines of evidence suggest that use of COX-2 selective NSAIDs may confer a reduced GI risk, particularly in the lower GI tract [13-15]. These observations have led to the publication of clinical guidelines that recommend the use of a nonselective NSAID plus a proton-pump inhibitor (PPI) or a COX-2 selective NSAID in patients with arthritis at risk of GI adverse events [1, 16-20].

However, while there are a limited number of studies comparing the efficacy and safety of celecoxib versus diclofenac [7, 21-25], there are very few studies in patients at high risk of GI adverse events. The CONDOR (Celecoxib versus Omeprazole and Diclofenac in Patients With Osteoarthritis and Rheumatoid Arthritis) trial, was the first prospective, large-scale clinical trial that showed that the risk of clinical outcomes across the entire GI tract was significantly reduced in patients with arthritis at high GI risk 
treated with celecoxib compared with those treated with diclofenac slow release (SR) plus omeprazole [7]. Treatment efficacy of celecoxib versus diclofenac SR plus omeprazole was also determined as a secondary outcome [7]. The aim of the present analysis was therefore to compare the effectiveness of celecoxib versus diclofenac plus omeprazole in improving arthritis signs and symptoms in patients at high GI risk who were enrolled in CONDOR.

\section{METHODOLOGY}

\section{Patients and Study Design}

CONDOR was a 6-month, prospective, double-blind, triple-dummy, parallel-group randomized trial conducted across 32 countries or territories. Patients with OA and/or RA with an increased risk of GI events were randomized 1:1 to receive either celecoxib $200 \mathrm{mg}$ twice daily (bid) or diclofenac SR $75 \mathrm{mg}$ bid plus omeprazole $20 \mathrm{mg}$ once daily (qd) for 6 months. The detailed inclusion and exclusion criteria, study design, and methods have been published previously [7] and are briefly discussed.

Patients with a clinical diagnosis of OA or RA were eligible for study entry if they were aged $\geq 60$ years, with or without a history of gastroduodenal ulceration, or were aged $\geq 18$ years and had documented evidence of gastroduodenal ulceration 90 days or more before screening. Patients also had to test negative for Helicobacter pylori at screening or have confirmed eradication of infection at a rescreening visit. Patients were excluded if they had a GI hemorrhage or active gastroduodenal ulceration within 90 days of screening and if they were concomitantly using antiplatelet (including aspirin) or anticoagulant therapy. Eligible patients were randomized to treatment at the baseline study visit and returned to the clinic at months 1, 2, 4, and 6 for assessments.

The study was conducted in accordance with Good Clinical Practice and the protocol was approved by local institutional review boards. All patients provided written informed consent.

\section{Efficacy Assessments}

The primary efficacy assessment was the Patients' Global Assessment of Arthritis; this efficacy assessment provides good test-retest reliability in arthritis [26]. The Patients' Global Assessment of Arthritis was determined at each study visit (screening, baseline, and months 1, 2, 4, and 6) by asking the following question: "Considering all the ways the OA or RA affects you, how are you doing today?" Patients rated their arthritis on a 5-point Likert scale, where 1 was very good and 5 very poor.

\section{Statistical Analyses}

All analyses in the study were based on the intention-totreat (ITT) population (unless otherwise stated); the ITT population included all patients who were randomized to treatment. Baseline demographics and characteristics were summarized using descriptive statistics. Treatment comparisons based on the Patients' Global Assessment of Arthritis were analyzed using a general linear model, including geographic region and history of gastroduodenal ulceration as fixed effects and Patients' Global Assessment of Arthritis at baseline as a covariate. A last observation carried forward approach was applied to the final visit. Responses were also summarized by category and compared between treatment groups using a Cochran-Mantel-Haenszel $(\mathrm{CMH})$ method. A p value $<0.05$ was considered statistically significant.

\section{RESULTS}

\section{Patients}

A total of 4484 patients were included in the ITT population (2238 celecoxib, 2246 diclofenac plus omeprazole). $1730(77.3 \%)$ patients treated with celecoxib and $1621(72.2 \%)$ patients treated with diclofenac SR plus omeprazole completed the study. Compliance with study medication was similar in both treatment groups (0.99 [0.03] celecoxib, 0.99 [0.05] diclofenac plus omeprazole).

The mean age of the study population was 65 years and the majority of patients were female $(82 \%)$. There were no major differences between treatment groups with respect to demographic or baseline characteristics (Table 1). The majority of patients had a diagnosis of OA $(84 \%$ [3774/4484] of patients versus $16 \%$ [710/4484] of patients with RA). The mean disease duration of OA was 7.6 years and 7.8 years in the celecoxib and diclofenac plus omeprazole groups, respectively. Mean disease duration of RA was 10.2 years for patients treated with celecoxib and 9.9 years for those treated with diclofenac plus omeprazole.

\section{Patients' Global Assessment of Arthritis}

Patients' Global Assessment of Arthritis was similar between treatment groups at baseline, with a least squares mean (LSM) (standard error [SE]) of 3.219 (0.017) for the celecoxib group and 3.221 (0.017) for the diclofenac SR plus omeprazole group $(\mathrm{p}=0.90)$ (Fig. 1). Improvement in both treatment arms was similar in months 2, 4, and 6; at month 1 the LSM (SE) was 2.647 (0.017) and 2.586 (0.017) for celecoxib and diclofenac $S R$, respectively $(p=0.0025)$. The LSM (SE) of Patients' Global Assessment of Arthritis at final visit or early termination (last observation carried forward) was $2.474(0.02)$ in the celecoxib group and 2.455 (0.02) in the diclofenac group.

The LSM difference (SE) from baseline to last observation carried forward demonstrated an improvement of $0.75(0.02)$ in celecoxib-treated patients and $0.77(0.02)$ in diclofenac plus omeprazole-treated patients $(p=0.42)$. These findings were reflected in the categorical summary of Patients' Global Assessment of Arthritis score; compared with baseline, more patients scored their arthritis as good or very good following 6 months of treatment with celecoxib or diclofenac plus omeprazole (Table 2). There was no significant difference in the categorical summary of Patients' Global Assessment of Arthritis score at the final visit between treatment groups using $\mathrm{CMH}(\mathrm{p}=0.9053)$.

\section{DISCUSSION}

When considering appropriate NSAID treatment strategies for individuals with arthritis, physicians must balance the efficacy alongside safety of the NSAIDs. This secondary analysis of data from the CONDOR trial demonstrates that celecoxib and diclofenac SR plus 
Table 1. Baseline Demographics and Characteristics in Patients with Arthritis Enrolled in the CONDOR Trial (ITT Population)

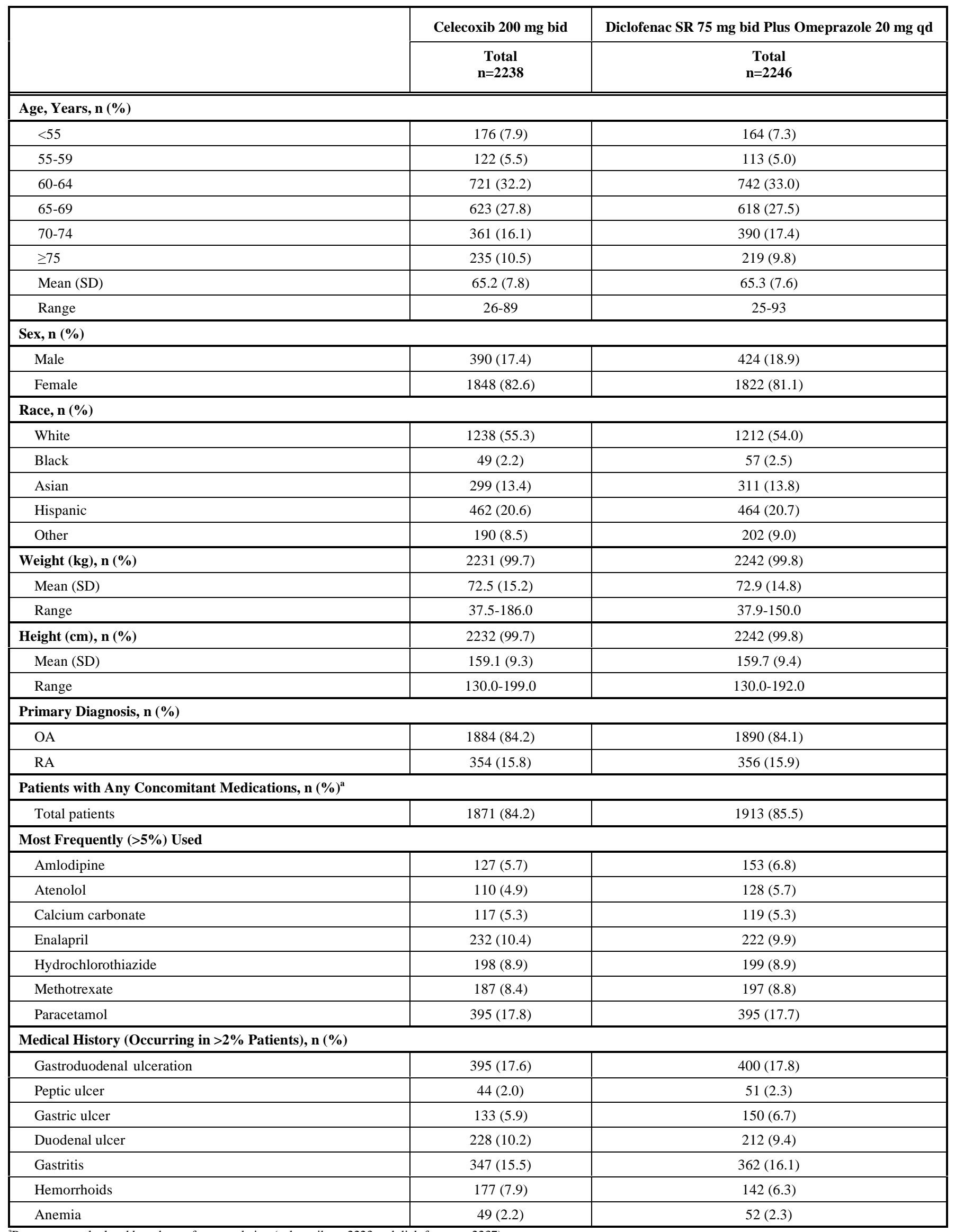




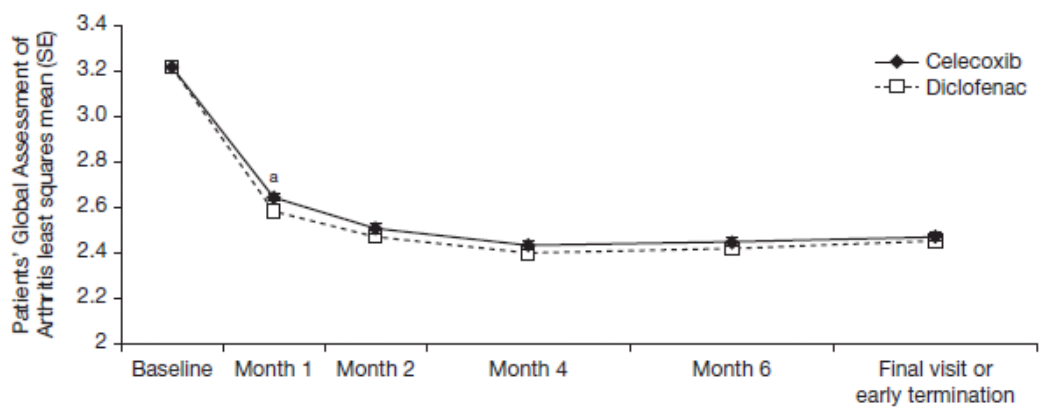

${ }^{a}$ Celecoxib versus diclofenac plus omeprazole; $p=0.0025$ (general linear model with fixed effects of geographic region and history of gastroduodenal ulceration).

Fig. (1). Improvements in the least squares mean of the Patients' Global Assessment of Arthritis from baseline to final visit or early termination in patients enrolled in the CONDOR study receiving celecoxib or diclofenac plus omeprazole

omeprazole have comparable efficacy in patients with OA and RA who are at increased GI risk. Patients in both treatment groups experienced an improvement in arthritis during the 6 months of the study as evidenced by a reduction in scores on the Patients' Global Assessment of Arthritis. Compared with baseline, more patients rated their arthritis as good or very good following 6 months of treatment with either intervention.

This study has shown that celecoxib and the nonselective NSAID diclofenac are equally efficacious in the treatment of $\mathrm{OA}$ and RA. These findings further support previous studies and meta-analyses in which celecoxib was consistently found to have similar efficacy to nonselective NSAIDs, including diclofenac and naproxen, in patients with OA or RA [21, 24, 27-30].

It should be noted that the dose of celecoxib (200 mg bid) studied in the CONDOR trial is the maximum licensed dose for the treatment of OA and RA [31], and, as such, may not accurately reflect the dose commonly used in current clinical practice. However, earlier studies assessing escalating doses of celecoxib indicate that $100-\mathrm{mg}$ bid and $200-\mathrm{mg}$ bid doses of celecoxib are similarly efficacious to one another and to nonselective NSAIDs in patients with OA or RA [27, 29].

Data from the CONDOR trial have demonstrated that, in patients at high GI risk, celecoxib is as efficacious as diclofenac SR plus omeprazole in improving the signs and symptoms of arthritis but it is associated with significantly fewer GI events. COX-2 selective NSAIDs and nonselective NSAIDs remain an important component of the therapeutic armamentarium for arthritis, provided the relative benefits and risks are assessed in individual patients.

\section{AUTHOR'S CONTRIBUTIONS}

H.L. Kellner - conduct of study, analysis and interpretation of data, critical revision/drafting of the manuscript, final approval to submit.

C. Li - statistical analysis and interpretation, critical revision/drafting of the manuscript, final approval to submit.

M.N. Essex - analysis and interpretation of data, critical revision/drafting of the manuscript, final approval to submit.
Table 2. Categorical Summary of Patients' Global Assessment of Arthritis Scores in Patients Enrolled in the CONDOR Trial Receiving Celecoxib or Diclofenac Plus Omeprazole

\begin{tabular}{|c|c|c|c|}
\hline Visit & Category & $\begin{array}{l}\text { Celecoxib } \\
200 \mathrm{mg} \text { bid } \\
\text { n }(\%)\end{array}$ & $\begin{array}{c}\text { Diclofenac SR } 75 \mathrm{mg} \\
\text { bid Plus Omeprazole } \\
20 \mathrm{mg} \text { qd } \\
\text { n }(\%)\end{array}$ \\
\hline \multirow{3}{*}{ Screening } & Good/Very good & $280(12.7)$ & 285 (12.9) \\
\hline & Fair & 1315 (59.7) & $1328(60.1)$ \\
\hline & Poor/Very poor & $608(27.6)$ & $598(27.0)$ \\
\hline \multirow{3}{*}{ Baseline } & Good/Very good & 237 (10.7) & $226(10.2)$ \\
\hline & Fair & $1286(58.3)$ & $1311(59.2)$ \\
\hline & Poor/Very poor & $684(31.0)$ & $676(30.5)$ \\
\hline \multirow{3}{*}{ Month 1} & Good/Very good & 877 (42.7) & $940(46.1)$ \\
\hline & Fair & 985 (47.9) & $939(46.1)$ \\
\hline & Poor/Very poor & $194(9.4)$ & $160(7.8)$ \\
\hline \multirow{3}{*}{ Month 2} & Good/Very good & $1021(52.0)$ & $999(53.3)$ \\
\hline & Fair & 815 (41.5) & $756(40.3)$ \\
\hline & Poor/Very poor & $129(6.6)$ & $121(6.4)$ \\
\hline \multirow{3}{*}{ Month 4} & Good/Very good & $1037(56.9)$ & $1001(58.1)$ \\
\hline & Fair & $683(37.5)$ & $630(36.6)$ \\
\hline & Poor/Very poor & $101(5.5)$ & $92(5.3)$ \\
\hline \multirow{3}{*}{ Month 6} & Good/Very good & $1214(57.0)$ & $1204(57.6)$ \\
\hline & Fair & 737 (34.6) & $723(34.6)$ \\
\hline & Poor/Very poor & $179(8.4)$ & $163(7.8)$ \\
\hline \multirow{3}{*}{ Final (LOCF) } & Good/Very good & $1250(56.6)$ & $1246(56.3)$ \\
\hline & Fair & $770(34.9)$ & 789 (35.7) \\
\hline & Poor/Very poor & $187(8.5)$ & $178(8.0)$ \\
\hline
\end{tabular}

$\mathrm{LOCF}=$ last observation carried forward.

\section{CONFLICT OF INTEREST}

H.L. Kellner - consultant/advisor for Pfizer and member of Pfizer's speakers' bureau.

C. Li- Pfizer Inc. full-time employee and shareholder. 
M.N. Essex - Pfizer Inc. full-time employee and shareholder.

\section{ACKNOWLEDGEMENTS}

The study was sponsored by Pfizer Inc, New York, NY, USA. Editorial support was provided by $\mathrm{K}$. Bradford, $\mathrm{PhD}$, and C. Campbell, PhD, of PAREXEL, UK and was funded by Pfizer Inc.

\section{REFERENCES}

[1] Hochberg MC, Altman RD, April KT, et al. American College of Rheumatology 2012 recommendations for the use of nonpharmacologic and pharmacologic therapies in osteoarthritis of the hand, hip, and knee. Arthritis Care Res 2012; 64(4): 465-74.

[2] Smolen JS, Aletaha D, Bijlsma JW, et al. Treating rheumatoid arthritis to target: recommendations of an international task force. Ann Rheum Dis 2010; 69(4): 631-7.

[3] Dai C, Stafford RS, Alexander GC. National trends in cyclooxygenase-2 inhibitor use since market release: nonselective diffusion of a selectively cost-effective innovation. Arch Intern Med 2005; 165(2): 171-7.

[4] Lanas A, Sopena F. Nonsteroidal anti-inflammatory drugs and lower gastrointestinal complications. Gastroenterol Clin North Am 2009; 38(2): 333-52.

[5] Allison MC, Howatson AG, Torrance CJ, Lee FD, Russell RI. Gastrointestinal damage associated with the use of nonsteroidal antiinflammatory drugs. N Engl J Med 1992; 327(11): 749-54.

[6] Graham DY, Opekun AR, Willingham FF, Qureshi WA. Visible small-intestinal mucosal injury in chronic NSAID users. Clin Gastroenterol Hepatol 2005; 3(1): 55-9.

[7] Chan FK, Lanas A, Scheiman J, Berger MF, Nguyen H, Goldstein JL. Celecoxib versus omeprazole and diclofenac in patients with osteoarthritis and rheumatoid arthritis (CONDOR): a randomised trial. Lancet 2010; 376(9736): 173-9.

[8] Rodriguez GLA, Jick H. Risk of upper gastrointestinal bleeding and perforation associated with individual non-steroidal antiinflammatory drugs. Lancet 1994; 343(8900): 769-72.

[9] Langman MJ, Weil J, Wainwright P, et al. Risks of bleeding peptic ulcer associated with individual non-steroidal anti-inflammatory drugs. Lancet 1994; 343(8905): 1075-8.

[10] U.S. Food and Drug Administration. COX-2 selective (includes Bextra, Celebrex, and Vioxx) and non-selective non-steriodial antiinflammatory drugs (NSAIDs). April, 2005. US FDA website. Available at: http://www.fda.gov/Drugs/DrugSafety/PostmarketDr ugSafetyInformationforPatientsandProviders/ucm103420.htm. Accessed March 9, 2012.

[11] Grosser T, Fries S, FitzGerald GA. Biological basis for the cardiovascular consequences of COX-2 inhibition: therapeutic challenges and opportunities. J Clin Invest 2006; 116(1): 4-15.

[12] Laine L. The gastrointestinal effects of nonselective NSAIDs and COX-2-selective inhibitors. Semin Arthritis Rheum 2002; 32 (3 Suppl 1): 25-32.

[13] Goldstein JL, Eisen GM, Lewis B, et al. Small bowel mucosal injury is reduced in healthy subjects treated with celecoxib compared with ibuprofen plus omeprazole, as assessed by video capsule endoscopy. Aliment Pharmacol Ther 2007; 25(10): 121122.

[14] Deeks JJ, Smith LA, Bradley MD. Efficacy, tolerability, and upper gastrointestinal safety of celecoxib for treatment of osteoarthritis and rheumatoid arthritis: systematic review of randomised controlled trials. BMJ 2002; 325(7365): 619.

[15] Goldstein JL, Eisen GM, Lewis B, Gralnek IM, Zlotnick S, Fort JG. Video capsule endoscopy to prospectively assess small bowel injury with celecoxib, naproxen plus omeprazole, and placebo. Clin Gastroenterol Hepatol 2005; 3(2): 133-41.

[16] American College of Rheumatology Subcommittee on Osteoarthritis Guidelines. Recommendations for the medical management of osteoarthritis of the hip and knee: 2000 update. American College of Rheumatology Subcommittee on Osteoarthritis Guidelines. Arthritis Rheum 2000; 43(9): 1905-15.

[17] Burmester G, Lanas A, Biasucci L, et al. The appropriate use of non-steroidal anti-inflammatory drugs in rheumatic disease: opinions of a multidisciplinary European expert panel. Ann Rheum Dis 2011; 70(5): 818-22.

[18] Chan FK, Abraham NS, Scheiman JM, Laine L. Management of patients on nonsteroidal anti-inflammatory drugs: a clinical practice recommendation from the First International Working Party on Gastrointestinal and Cardiovascular Effects of Nonsteroidal Antiinflammatory Drugs and Anti-platelet Agents. Am J Gastroenterol 2008; 103(11): 2908-18.

[19] Jordan KM, Arden NK, Doherty M, et al. EULAR Recommendations 2003: an evidence based approach to the management of knee osteoarthritis: Report of a Task Force of the Standing Committee for International Clinical Studies Including Therapeutic Trials (ESCISIT). Ann Rheum Dis 2003; 62(12): 1145-55.

[20] Zhang W, Doherty M, Arden N, et al. EULAR evidence based recommendations for the management of hip osteoarthritis: report of a task force of the EULAR Standing Committee for International Clinical Studies Including Therapeutics (ESCISIT). Ann Rheum Dis 2005; 64(5): 669-81.

[21] Emery P, Zeidler H, Kvien TK, et al. Celecoxib versus diclofenac in long-term management of rheumatoid arthritis: randomised double-blind comparison. Lancet 1999; 354(9196): 2106-11.

[22] Schwartz JI, Dallob AL, Larson PJ, et al. Comparative inhibitory activity of etoricoxib, celecoxib, and diclofenac on COX-2 versus COX-1 in healthy subjects. J Clin Pharmacol 2008; 48(6): 745-54.

[23] Silverstein FE, Faich G, Goldstein JL, et al. Gastrointestinal toxicity with celecoxib $v s$ nonsteroidal anti-inflammatory drugs for osteoarthritis and rheumatoid arthritis: the CLASS study: a randomized controlled trial. Celecoxib Long-term Arthritis Safety Study. JAMA 2000; 284(10): 1247-55.

[24] Singh G, Fort JG, Goldstein JL, et al. Celecoxib versus naproxen and diclofenac in osteoarthritis patients: SUCCESS-I Study. Am J Med 2006; 119(3): 255-66.

[25] Chan FK, Hung LC, Suen BY, et al. Celecoxib versus diclofenac and omeprazole in reducing the risk of recurrent ulcer bleeding in patients with arthritis. N Engl J Med 2002; 347(26): 2104-10.

[26] Rohekar G, Pope J. Test-retest reliability of patient global assessment and physician global assessment in rheumatoid arthritis. J Rheumatol 2009; 36(10): 2178-82.

[27] Bensen WG, Fiechtner JJ, McMillen JI, et al. Treatment of osteoarthritis with celecoxib, a cyclooxygenase-2 inhibitor: a randomized controlled trial. Mayo Clin Proc 1999; 74(11): 1095105.

[28] Moore RA, Derry S, Makinson GT, McQuay HJ. Tolerability and adverse events in clinical trials of celecoxib in osteoarthritis and rheumatoid arthritis: systematic review and meta-analysis of information from company clinical trial reports. Arthritis Res Ther 2005; 7(3): R644-R665.

[29] Simon LS, Weaver AL, Graham DY, et al. Anti-inflammatory and upper gastrointestinal effects of celecoxib in rheumatoid arthritis: a randomized controlled trial. JAMA 1999; 282(20): 1921-8.

[30] McKenna F, Borenstein D, Wendt H, Wallemark C, Lefkowith JB, Geis GS. Celecoxib versus diclofenac in the management of osteoarthritis of the knee. Scand J Rheumatol 2001; 30(1): 11-8.

[31] Celebrex [package insert]. Pfizer Inc., New York: NY 2013. 